\title{
EFEITO DE EXTRATOS AQUOSOS DE PLANTAS MEDICINAIS NATIVAS DO RIO GRANDE DO SUL SOBRE A GERMINAÇÃO DE SEMENTES DE ALFACE
}

\section{THE EFFECT OF AQUEOUS EXTRACTS OF MEDICINAL PLANTS NATIVE TO RIO GRANDE DO SUL ON THE GERMINATION OF LETTUCE SEEDS}

\author{
Sérgio Alessandro Machado Souza ${ }^{{ }^{*}}$, Letícia Vesz Cattelan ${ }^{1}$, \\ Daiane Peixoto Vargas ${ }^{1}$, Clause Fátima de Brum Piana ${ }^{2}$, \\ Vera Lucia Bobrowski ${ }^{1}$, Beatriz Helena Gomes Rocha ${ }^{1}$ \\ $1^{*}$ Autor para contato: Universidade Federal de Pelotas - UFPel, Instituto de Biologia, \\ Departamento de Zoologia e Genética, Laboratório de Genética, Pelotas, RS, Brasil; \\ (53) 3275-7138; e-mail: sergiobioufpel@yahoo.com.br \\ 2 Universidade Federal de Pelotas - UFPel, Departamento de Fitotecnia, Pelotas, RS
}

Recebido para publicação em 18/08/2005

Aceito para publicação em 22/11/2005

\section{RESUMO}

O efeito de extratos aquosos sobre a germinação de sementes pode ser avaliado pela atividade alelopática, a qual se refere à capacidade que determinados compostos fitoquímicos possuem de interferir na germinação ou no desenvolvimento de plantas. Este trabalho teve como objetivo avaliar o efeito do extrato aquoso de plantas medicinais nativas do Rio Grande do Sul, Mikania glomerata Spreng., Achyrocline satureioides (Lam.) DC., Bauhinia candicans Benth., Casearia sylvestris Sw., Luehea divaricata Mart. et. Zucc. e Lippia alba (Mill.) N.E. Br., sobre a germinação de sementes de alface. Os bioensaios foram conduzidos em germinador $\left(20^{\circ} \mathrm{C}\right)$, com extrato aquoso obtido por infusão de folhas secas nas concentrações de 5, 10, 20 e $40 \mathrm{mg} / \mathrm{mL}$, e água destilada (controle). Os testes de germinação, primeira contagem e o índice de velocidade de germinação (IVG), que avaliam o efeito alelopático, foram feitos com quatro repetições de 100 sementes/concentração. Verificou-se o efeito dos extratos aquosos sobre a germinação de sementes de alface de todas as espécies medicinais analisadas, mas esse foi mais evidente em B. candicans, L. divaricata. e L. alba, demonstrando, assim, que essas espécies medicinais são potencialmente alelopáticas.

Palavras-chave: alelopatia, germinação, plantas medicinais, fitotoxicidade, extrato aquoso 


\begin{abstract}
The effect of aqueous extracts on the germination of seeds can be evaluated by means of the allelopathic activity. Allelopathy refers to the capacity that certain phytochemical compounds possess of interfering in the germination or in the development of plants. This work had the objective to evaluate the allelopathic effect of aqueous extracts of medicinal plants native to Rio Grande do Sul, Mikania glomerata Spreng., Achyrocline satureioides (Lam.) DC., Bauhinia candicans Benth., Casearia sylvestris Sw., Luehea divaricata Mart. et. Zucc. and Lippia alba (Mill.) N.E., on the germination of lettuce seeds. Bioassays were carried out in a germinator, at $20^{\circ} \mathrm{C}$, with aqueous extracts obtained by infusions of dry leaves, in the concentrations of 5, 10, 20 and $40 \mathrm{mg} / \mathrm{mL}$, and distilled water (control). The germination test, first score and germination speed rate (GSR), that evaluate the allelopathic effect, were done with four repetitions of 100 seeds/concentration. The results showed good effects of all the analysed medicinal species on the germination of lettuce seed, but this effect was more significant in relation to B. Candians, L. divaricata and L. alba, which demonstrates that these three species are potentially allelopathic.
\end{abstract}

Key words: allelopathy, germination, medicinal plants, phytotoxicity, aqueous extract

\section{Introdução}

A utilização de plantas medicinais nativas no tratamento de enfermidades é uma prática exploratória e largamente difundida no Brasil. Amaioria das espécies tem sido utilizada de forma extrativista, sendo que o crescimento da população humana e a ocupação de áreas naturais vêm aumentando a pressão destrutiva sobre essa flora (Rosa e Ferreira, 2001).

A importância das plantas medicinais deve-se a sua contribuição como fonte natural de fármacos e por proporcionar grandes chances de obter-se uma molécula protótipo devido à diversidade de constituintes presentes (Yunes e. Calixto, 2001). Entretanto, inúmeras plantas que são usadas em preparações fitoterápicas carecem de um maior controle de qualidade, uma vez que a literatura científica indica que muitas dessas podem apresentar substâncias tóxicas ou composição química variável (Capasso et al., 2000).

A presença de substâncias químicas como compostos fenólicos, cumarinas, terpenóides, flavonóides, alcalóides, glicosídeos, taninos e quinonas, que são encontradas como metabólitos secundários dos vegetais podem desencadear efeitos benéficos ou maléficos sobre outros vegetais ou demais organismos. O efeito alelopático dessas substâncias se refere à capacidade que as plantas tem de inibir a germinação de sementes ou o desenvolvimento de outras espécies (Rodrigues e Lopes, 2001).

Segundo Chou e Kuo (1986), a fitotoxicidade de extratos sobre várias plantas ou demais organismos é atribuída à diversidade de aleloquímicos presentes em sua composição, originados do metabolismo secundário dos vegetais. No entanto, a maioria dos estudos com alelopatia referem-se a ação de plantas daninhas sobre cultivares, espécies exóticas sobre nativas e poucos são os trabalhos em relação a espécies medicinais nativas (Prates et al., 2001).

Mikania glomerata Spreng. (Asteraceae), conhecida popularmente como guaco, é uma trepadeira sublenhosa, perene, com folhas obtusas, encontrada como nativa em toda a região sul do Brasil. Segundo Lorenzi (2002), essa planta é utilizada na medicina tradicional, onde se atribuem às suas folhas as seguintes propriedades: ação tônica, depurativa, febrífuga, peitoral e antigripal. Sua análise fitoquímica comprovou a presença de cumarina e outras substâncias dela derivadas (Simões et al., 1986). 
Achyrocline satureioides (Lam.) DC. (Asteraceae), conhecida como marcela, é uma planta herbácea perene, com inúmeras ramificações, com folhas simples, encontrada nativa em campos da campanha gaúcha e também, até o norte do estado do Paraná (Lorenzi, 2002). Na medicina caseira, seu uso é atribuído no tratamento de problemas gástricos, epilepsia e cólicas de origem nervosa. Muitas vezes, também é empregada como antiinflamatória, analgésica e contra a diarréia (Lorenzi, 2002). As análises químicas desse táxon mostraram que ele é constituído por flavonóides e monoterpenos, sendo muitas dessas substâncias responsáveis pelas suas propriedades medicinais (Martins et al., 2000).

Bauhinia candicans Benth. (Caesalpiniaceae), uma das cerca de 300 espécies do gênero Bauhinia, apresenta-se como uma árvore de porte arbóreo, semidecídua, encontrada do Sudeste ao Sul do Rio Grande do Sul, possuindo folhas uncinadas com formato semelhante a uma pata-de-vaca, designando assim, o seu nome popular (Martins et al., 2000). A B. candicans é utilizada na medicina popular brasileira como agente diurético, hipoglicemiante, tônico, depurativo, no combate à elefantíase e na redução da glicosúria (Lorenzi, 2002).

Casearia sylvestris Sw. (Flacourtiaceae), conhecida popularmente como chá-de-bugre, é uma planta de porte arbóreo, dotada de uma copa densa e arredondada. Essa planta é nativa em quase todo o território nacional, mas é encontrada, principalmente, no Planalto Meridional (Lorenzi, 2002). Tem suas folhas amplamente utilizadas na medicina tradicional, no tratamento de queimaduras e da herpes, mas a grande utilização do chá-de-bugre, hoje, é como diurético e redutor de apetite, tendo assim despertado grande interesse na indústria farmacêutica (Lorenzi, 2002).

Luehea divaricata Mart. et. Zucc. (Tiliaceae), popularmente conhecida como açoita-cavalo, é uma árvore decídua que apresenta grande importância devido a presença de fibras extremamente resistentes que compõem o vegetal (Backes e Irgan, 2003). Sua aplicação medicinal esta voltada ao tratamento de bronquite, laringite e disenteria, sendo suas folhas usadas por decocção ou infusão. Os estudos fitoquímicos do açoita-cavalo indicam que esse vegetal apresenta grande quantidade de taninos e monoterpenos, tanto na casca como no caule (Lorenzi, 2002).
Lippia alba (Mill.) N.E. Br. (Verbenaceae), é um subarbusto com ramos arqueados, folhas inteiras com bordas serreadas, nativo em toda a região sul do Brasil (Lorenzi, 2002). O chá-de-sálvia, como a espécie é designada popularmente, é utilizado como analgésico, devido à presença de grande quantidade de mirceno. Apresenta atividade calmante e espasmolítica, atribuídas a presença de citral, que desempenha um efeito mucolítico, pois facilita a expectoração (Lorenzi, 2002). De acordo com o mesmo autor, mirceno, citral e limonemo são os compostos fitoquímicos monoterpênicos presentes em quantidades relativamente altas, principalmente na parte aérea.

A utilização de bioensaios vegetais para o monitoramento de substâncias ou frações de compostos isolados de plantas é uma excelente ferramenta, sendo desenvolvida com sementes de espécies sensíveis (Noldin et al., 2003). De acordo com Ferreira e Aquila (2000), o efeito alelopático de substâncias químicas é mais ou menos específico, existindo assim, espécies mais sensíveis do que outras, por exemplo, alface (Lactuca sativa L.) e tomate (Lycopersicum esculentum L.).

O presente estudo teve como objetivo avaliar o efeito do extrato aquoso de plantas medicinais nativas do Rio Grande do Sul, Mikania glomerata Spreng. (Asteraceae), Achyrocline satureioides (Lam.) DC. (Asteraceae), Bauhinia candicans Benth. (Caesalpiniaceae), Casearia sylvestris Sw. (Flacourtiaceae), Luehea divaricata Mart. et. Zucc. (Tiliaceae) e Lippia alba (Mill.) N.E. Br. (Verbenaceae), sobre a germinação de sementes de alface, que é um organismo altamente sensível ao estresse ambiental, através do teste de primeira contagem, germinação, Índice de Velocidade de Germinação (IVG), testes usuais para monitorar efeitos alelopático.

\section{Material e métodos}

O presente trabalho foi realizado no Laboratório de Genética do Departamento de Zoologia e Genética do Instituto de Biologia da Universidade Federal de Pelotas (UFPel) RS. 


\subsection{Plantas medicinais}

As amostras foram coletadas de exemplares cultivados/nativos do setor de paisagismo-espécies medicinais do Conjunto Agrotécnico Visconde da Graça (CAVG-UFPel), localizado no município de Pelotas ( $31^{\circ} 45^{\prime} \mathrm{S}, 5^{\circ} 21^{\prime} \mathrm{W}$ ) RS entre os meses de dezembro de 2004 e fevereiro de 2005, e a identificação correta das espécies com o auxilio de chaves classificatórias (Barroso, 1978, 1991, 1991; Cronquist, 1988; Joly, 1985). Foram utilizadas folhas de $M$. glomerata (guaco) B. candicans (pata-de-vaca), $C$. sylvestris (chá-de-bugre), L. divaricata (açoitacavalo), L. alba (sálvia) e capítulos florais de $A$. satureioides (marcela) e essas espécies comparadas com exsicatas pertencentes ao Herbário-Pel da UFPel, catalogadas, respectivamente, sob os números: (Pel 11.489), (Pel 17.107), (Pel 10.586), (Pel 21.060), (Pel 23.178) e (Pel 19.986).

\subsection{Extrato aquoso}

Para a obtenção dos extratos aquosos das espécies indicadas no item 2.1, as partes vegetais utilizadas foram pesadas em balança analítica, colocadas em erlenmeyer ( $500 \mathrm{~mL}$ ), adicionando-se após, água destilada em ebulição. Os recipientes foram hermeticamente fechados e deixados em repouso por 10 minutos. Após filtragem, o extrato aquoso obtido foi diluído de modo a obter-se quatro concentrações diferentes de cada espécie vegetal (5; 10; 20; e 40 mg/mL).

\subsection{Bioensaio}

Como organismo-teste, foram utilizadas sementes de alface. Essas foram submetidas a resfriamento de $4^{\circ} \mathrm{C}$ por $72 \mathrm{~h}$, para superação da dormência. Os bioensaios foram realizados em câmara de germinação com temperatura controlada de $20^{\circ} \mathrm{C}$. As sementes de alface foram acondicionadas em caixas gerbox $(11 \times 11 \mathrm{~cm})$, forradas com papel mataborrão umedecido com $10 \mathrm{~mL}$ de cada extrato ou água destilada (controle negativo). Foram utilizadas 4 repetições estatísticas de 100 sementes, para cada concentração dos extratos e do controle, em delineamento estatístico inteiramente casualizado.

Foram realizadas contagens diárias para o índice de velocidade de germinação (IVG), aos quatro dias (teste de primeira contagem) e aos sete dias (teste de germinação ou germinabilidade), segundo as regras para análise de sementes (Brasil, 1992).

\subsection{Análise estatística}

As variáveis analisadas foram: primeira contagem, germinação e IVG. As variáveis primeira contagem e germinação foram transformadas segundo o arco seno de $\sqrt{x / 100}$.

A análise estatística dos dados consistiu de análise da variação e de decomposição da variação dos fatores através de regressão polinomial, para o fator concentração. Na regressão polinomial, os critérios utilizados para a adoção do modelo foram a significância $(a=0,05)$ e o coeficiente de determinação $\left(\mathrm{R}^{2}\right)$ do mesmo. Estabeleceu-se arbitrariamente o valor mínimo para o $\mathrm{R}^{2}$ de 0,6.

As análises estatísticas foram executadas pelo programa WinStat - sistema de análise estatística para Windows - Versão Beta (Machado e Conceição, 2005).

\section{Resultados e discussão}

Na figura 1 (A,D), observou-se que as concentrações do extrato aquoso de $M$. glomerata (guaco) e C. sylvestris (chá-de-bugre) acarretaram um decréscimo nos valores da variável primeira contagem, até concentrações próximas a $30 \mathrm{mg} / \mathrm{mL}$, e após promoveram um novo aumento. Alves et al. (2004) verificaram efeito semelhante de componentes voláteis extraídos do óleo essencial de Pilocarpus microphyllus Stapf ex Ward. (jaborandi), onde as concentrações intermediárias também acarretaram um pequeno efeito inibitório sobre a germinação de sementes de alface.

Com relação ao extrato aquoso de $A$. satureioides (marcela) (Figura1B), ocorreu um aumento da variável analisada até a concentração de $10 \mathrm{mg} / \mathrm{mL}$. Isso indica que, as menores concentrações não demonstram efeito fitotóxico para sementes de 
alface. Em muitos casos, observa-se que uma substância pode estimular o crescimento vegetal em baixas concentrações e inibir em concentrações mais altas (Rice, 1984).

A ação do extrato aquoso de L. alba (sálvia) demonstrou uma ação inversamente proporcional a variável em questão (Figura 1F). Esses dados corroboram com os estudos de Pires et al. (2001), onde o aumento das concentrações do extrato aquoso de Leucaena leucocephala (Lam.) de Wit. (leucena) apresentou efeito tóxico na germinação de sementes
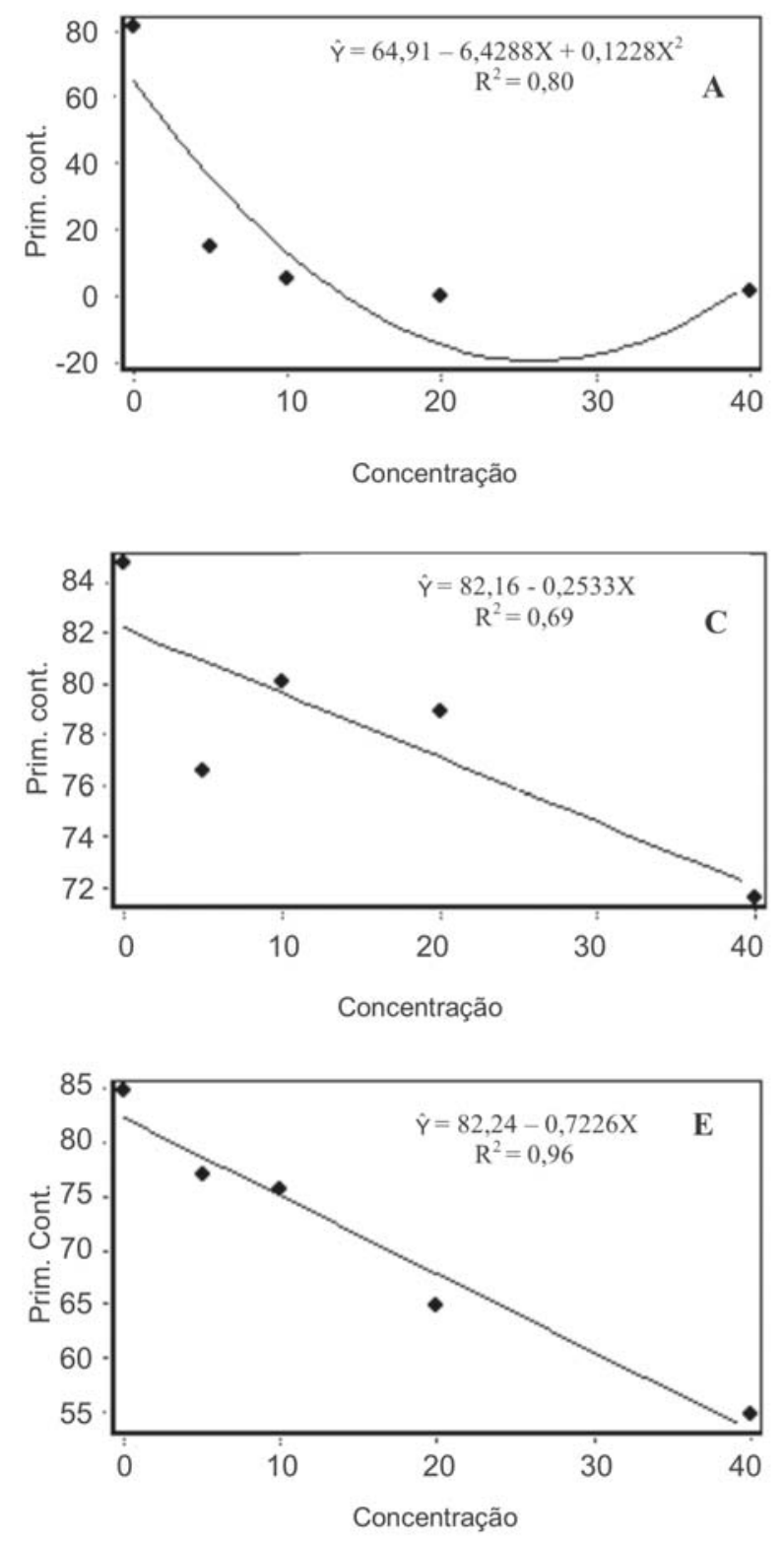

de picão-preto e caruru.

Na figura 1(C,E), evidenciou-se que o aumento das concentrações dos extratos aquosos de $B$. candicans (pata-de-vaca) e L. divaricata (açoitacavalo) promoveram uma diminuição da variável primeira contagem. Segundo Rodrigues et al. (1992), os compostos alelopáticos são inibidores de germinação e crescimento, influenciando diretamente na emissão das radículas das plantas em teste, pois interferem na divisão celular, na permeabilidade das membranas e na ativação de enzimas.
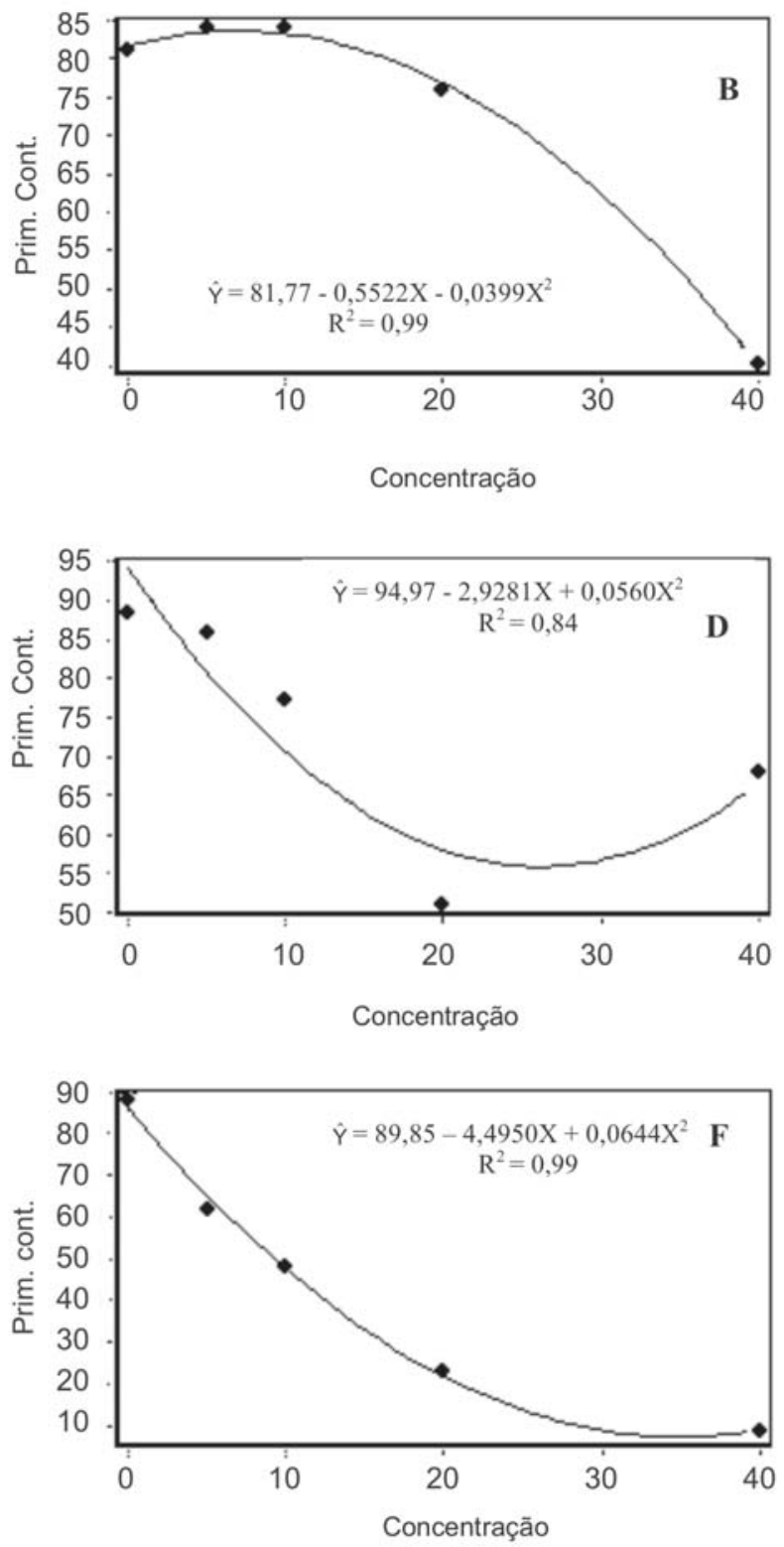

Figura 1 - Gráficos das curvas ajustadas e das médias observadas para a variável primeira contagem, para sementes de alface tratadas com diferentes extratos aquosos de Mikania glomerata Spreng. (guaco) (A), Achyrocline satureioides (Lam.) DC. (marcela) (B), Bauhinia candicans Benth. (pata-de-vaca) (C), Casearia sylvestris Sw. (chá-de-bugre) (D), Luehea divaricata Mart. et. Zucc. (açoita-cavalo) (E) e Lippia alba (Mill.) N.E. Br.(sálvia) (F). 
Na figura 2 (A,B,D), observou-se que o aumento da concentração do extrato de M. glomerata, A. satureioides e $C$. sylvestris levaram a um decréscimo nos valores da germinação, até concentrações próximas a $30 \mathrm{mg} / \mathrm{mL}$, e em seguida, proporcionaram um novo aumento da germinabilidade. Esses dados estão de acordo com os encontrados por Reigosa et al.(1999), onde relatam que os efeitos dos aleloquímicos nos diferentes processos fisiológicos de uma planta são dependentes das concentrações, ou ao menos, se espera que sejam. Os autores ainda afirmam que são comuns os efeitos em "serra-dente” (concentrações baixas favorecem a germinação, intermediárias inibem e altas concentrações favorecem o percentual germinativo), visto que a quantificação de efeitos secundários reflete a soma não-linear de vários efeitos primários.

O incremento da concentração do extrato aquo- so de L. alba levou a uma inibição da germinabilidade, sendo representado, na figura $2 \mathrm{~F}$. Carvalho et al.(1996), também verificaram que o potencial alelopático de folhas verdes de Saccharum officinarium L. (cana-de-açúcar), sobre sementes de Mimosa caesalpinaefolia Benth. (sabiá), variava em função das concentrações analisadas.

Foi verificado o potencial alelopático do extrato aquoso de $B$. candicans (Figura 2C) e de $L$. divaricata (Figura 2E), pois, o aumento da concentração promoveu uma diminuição da percentagem de germinação. Gatti et al. (2004), em estudos sobre o efeito do extrato obtido das folhas de Aristolochia esperanzae O. Kuntze (papo-de-peru) sobre a germinação de sementes de alface e de rabanete, observaram que o extrato aquoso obtido das folhas inibiu a germinação das sementes nos bioensaios, com o aumento das concentrações analisadas. 

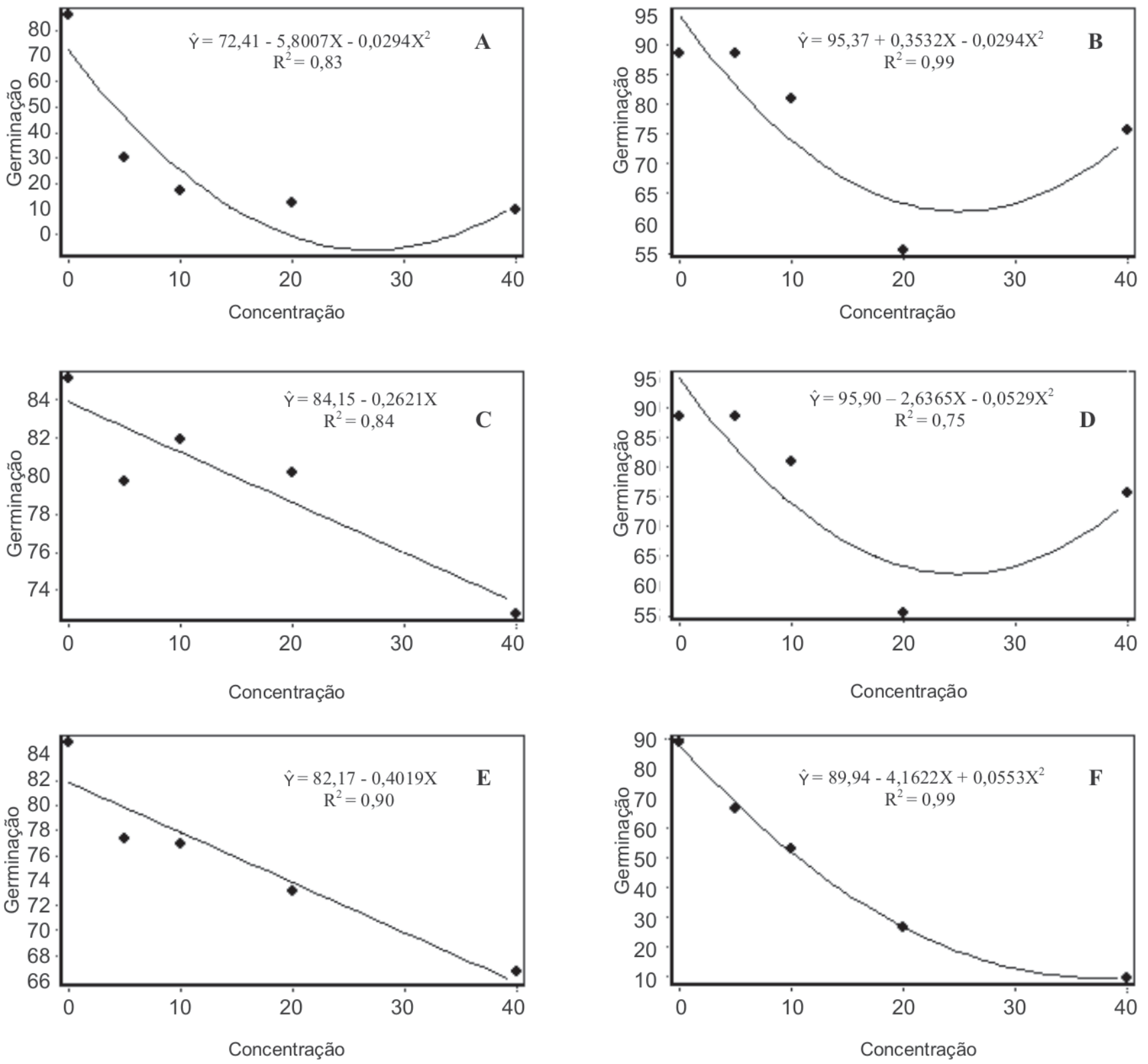

Figura 2 - Gráficos das curvas ajustadas e das médias observadas para a variável germinação, para sementes de alface tratadas com diferentes extratos aquosos de Mikania glomerata Spreng. (guaco) (A), Achyrocline satureioides (Lam.) DC. (marcela) (B), Bauhinia candicans Benth. (pata-de-vaca) (C), Casearia sylvestris Sw. (chá-de-bugre) (D), Luehea divaricata Mart. et. Zucc. (açoita-cavalo) (E) e Lippia alba (Mill.) N.E. Br.(sálvia) (F).

O extrato aquoso de $M$. glomerata (Figura 3A) inibiu drasticamente o IVG, demonstrando assim a sua toxicidade. Esses resultados corroboram com os encontrados por Colpas et al. (2003), trabalhando com vários compostos secundários, entre eles, cumarinas, composto presente em M. glomerata, evidenciaram uma forte atividade inibitória sobre a germinação de semente de soja.
Para as espécies medicinais $A$. satureioides e B. candicans (Figura 3B,C), foi observado que o aumento da concentração promoveu um decréscimo da variável analisada. Segundo Ferreira e Borghetti (2004), freqüentemente, o efeito alelopático pode não se dar sobre a germinabilidade (percentual final de germinação), mas sobre a velocidade de germinação ou sobre outro parâmetro do processo. 


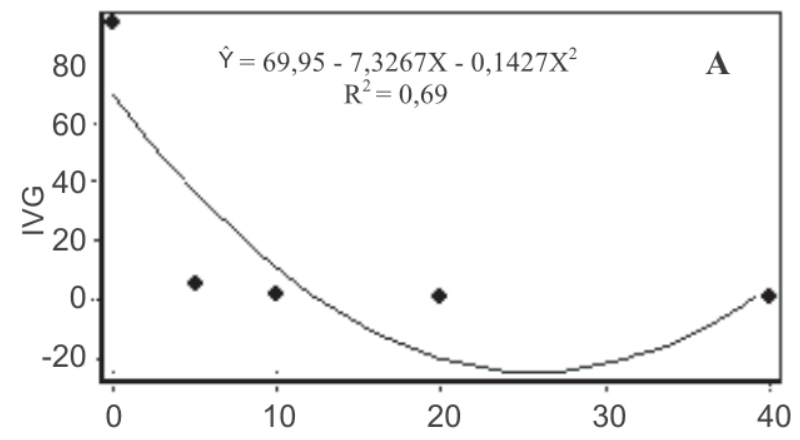

Concentração
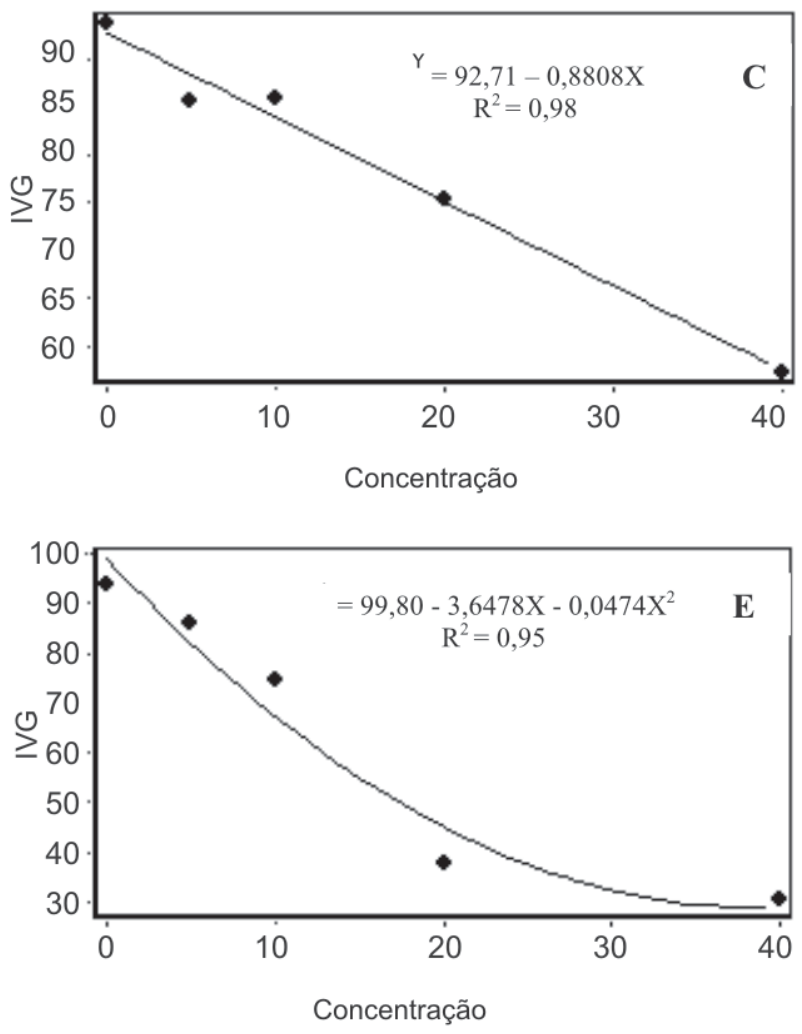
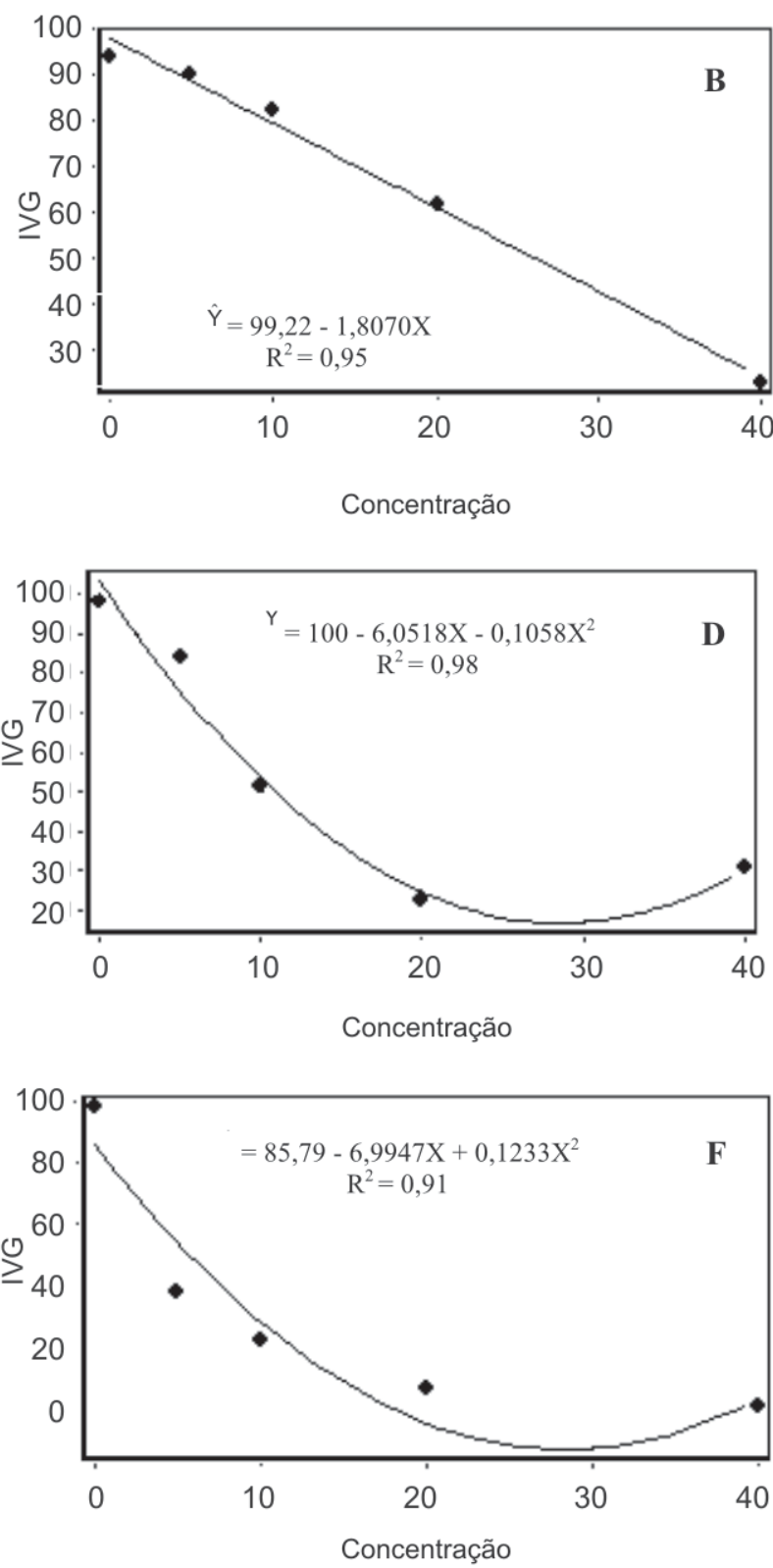

Figura 3 - Gráficos das curvas ajustadas e das médias observadas para a Índice de Velocidade de Germinação, para sementes de alface tratadas com diferentes extratos aquosos de Mikania glomerata Spreng. (guaco) (A), Achyrocline satureioides (Lam.) DC. (marcela) (B), Bauhinia candicans Benth. (pata-de-vaca) (C), Casearia sylvestris Sw. (chá-de-bugre) (D), Luehea divaricata Mart. et. Zucc. (açoita-cavalo) (E) e Lippia alba (Mill.) N.E. Br.(sálvia) (F).

Os extratos aquosos de $C$. sylvestris e $L$. alba (Figura 3D,F) demonstraram uma redução do IVG entre os pontos de 20 e $40 \mathrm{mg} / \mathrm{mL}$. Resultados semelhantes foram verificados por Prates et al. (2001), em sementes de milho tratadas com extrato aquoso de $L$. leucocephala (leucena). Os autores observaram que os extratos dessa planta inibiram o IVG e a divisão celular dos meristemas radiculares da espécie-teste.

Na figura 3E, verificou-se que o incremento da concentração do extrato aquoso de $L$. divaricata, levou a uma redução da variável IVG. Conforme Mazzafera (2003), o extrato aquoso de Syzygium aromaticum (L.) Merr. e Perry (cravo-da-índia) apresentou uma forte inibição na germinação e na velocidade de germinação de várias sementes, entre elas, alface e tomate, demonstrando também o potencial alelopático da espécie. Carvalho et al. (1996) ressaltam a importância de estudos e da identificação de plantas 
com propriedades alelopáticas, tanto na utilização de cultivares agrícolas capazes de inibir plantas daninhas, quanto na determinação de práticas culturais e de manejos mais adequados.

\section{Conclusões}

- Os extratos aquosos das espécies medicinais analisadas acarretam efeitos inibitórios sobre a germinação de sementes de alface.

- O efeito alelopático foi mais evidente em $B$. candicans (pata-de-vaca), L. divaricata (açoita-cavalo) e L. alba (sálvia), demonstrando assim a atividade fitotóxica dessas espécies.

Agradecimentos

Ao Professor Dr Marcio Paim Mariot do Conjunto Agrotécnico Visconde da Graça (CAVGUFPel) pela coleta e identificação das espécies, e aos estagiários do Herbário da UFPel (Herbário-Pel) Karina Maculan e Márcio Provenci pelo auxilio na identificação das espécies.

\section{REFERÊNCIAS}

1. ALVES, M.C.S.; MEDEIROS-FILHO, S; INNECCO, R.; TORRES, S.B. Alelopatia de extratos voláteis na germinação de sementes e no comprimento da raiz de alface. Pesquisa Agropecuária Brasileira, Brasília-DF, v.39, n.11, p.1083-1086, 2004.

2. BACKES, P.; IRGANG, B. Árvores do sul, Porto Alegre. Instituto Souza Cruz. 2003. 326p

3. BARROSO, G.M. Sistemática de Angiospermas no Brasil v.1. São Paulo. EDUSP. 1978. 255p.

4. BARROSO, G.M. Sistemática de Angiospermas no Brasil v.2 .São Paulo. EDUSP. 1991. 377p.

5. BARROSO, G.M. Sistemática de Angiospermas no Brasil v.3. São Paulo. EDUSP. 1991. 326p.

6. BRASIL. Ministério da Agricultura e Reforma Agrária. Divisão de Laboratório Vegetal. Regras para Análise de Sementes, Brasília. 1992. 365p.

7. CAPASSO, R.; IZZO, A.A.; PINTO, L.; BIFULCO, T.; VITOBELLO, C.; MASCOLO, M. Fitoterapia, v.58, p.71, 2000.

8. CARVALHO, G.J.; ANDRADE, L.A.B.; GOMIDE, M.;
FIGUEIREDO, P.A.M. Potencialidades alelopáticas de folhas verdes de cana-de-açúcar em diferentes concentrações de matéria seca na germinação de sementes de alface. Ciências, Marília-SP, v.5, n.2, p.19-24, 1996.

9. CHOU, C.H.; KUO, Y.L. Allelopathic exclusion of understory by Leucena leucocephala (Lam.). Journal of Chemical Ecology, v.12, n.1, p.1434-1448, 1986.

10. COLPAS, F.T.; ONO, E. O.; RODRIGUES, J. D. Effects of some phenolic compounds on soybean seed germination and on seed-borne fungi. Brazilian Archives Biology and Technology, v.46, n.2, p.155-161, 2003.

11. CRONQUIST, A. The Evolution and Classification of Flowering Plants 2ed. Bronx: New York Botanical. 1988. 555p.

12. FERREIRA, A.G.; AQUILA, M.E.A. Alelopatia: Uma área emergente da ecofisiologia vegetal. Revista Brasileira de Fisiologia Vegetal, São Paulo, v.12, n.1, p.175-204. 2000.

13. FERREIRA, A.G.; BORGHETTI, F. Germinação: do básico ao aplicado. Porto Alegre, Artmed, 2004.520p.

14. GATTI, A.B.; PEREZ, S.C.J.G.A.; LIMA, M.I.S. Atividade alelopática de extratos aquosos de Aristolochia esperanzae O. Kuntze na germinação e no crescimento de Lactuca sativa L. e Raphanus sativus L. ACTA Botânica Brasílica, v.18, n.3, p.459-472, 2004.

15. JOLY, A.B. Botânica: Introdução a taxonomia vegetal. 7 ed. São Paulo, Nacional.1985. 778p.

16. LORENZI, H. Plantas Medicinais no Brasil. São Paulo, Plantarum, 2002.512p.

17. MACHADO, A.A.; CONCEIÇÃO, A.R. WinStat - Sistema de Análise Estatística para Windows. Versão Beta. Universidade Federal de Pelotas, 2005.

18. MARTINS, R. E.; CASTRO, D. M.; CASTELLANI, D. C.; DIAS, J. E. Plantas Medicinais. Viçosa-Minas Gerais. UFV. 2000.220p

19. MAZZAFERA, P. Efeito alelopático do extrato aquoso de cravo-da-índia e eugenol. Revista Brasileira de Botânica, v.26, n.2, p.231-238, 2003.

20. NOLDIN, V.F.; MONACHE, F.D.; YUNES, R.A. Composição química e atividade biológica de Cynara scolymus L. cultivada no Brasil. Química Nova, São Paulo, v.26, n.3, p.331-334, 2003.

21. PIRES, N.M.; PRATES, H.T.; PEREIRA, I.A.; OLIVEIRA, R.S.; FARIA, T.C.L. Atividade alelopática da leucena sobre espécies de plantas daninhas. Scientia Agrícola, São Paulo. v.58, n.1, p. 61-65, 2001.

22. PRATES, H.T.; PAES, J.M.V.; PIRES, N.M.; PEREIRA, I.A.; MAGALHÃES, P.C. Efeito do extrato aquoso de leucena na germinação e no desenvolvimento do milho. Pesquisa Agropecuária Brasileira, v.35, n.1, p.909-914, 2001.

23. REIGOSA, M.J.; SÁCHES-MOREIRAS,A.; GONZALES, 
L. Ecophysiological approach in allelopathy. Critical Reviews in Plant Science, v.18, n.5, p.577-608, 1999.

24. RODRIGUES, F.C.M.P.; LOPES, B.M. Potencial Alelopático de Mimosa caesalpinaefolia Benth sobre sementes de Tabebuia Alba (Cham.) Sandw. Floresta e Ambiente, Rio de Janeiro, v.8, n.1, p.130-136, 2001.

25. RODRIGUES, L.R.A.; RODRIGUES, T.J.D.; REIS, R.A. Alelopatia em plantas forrageiras. Jaboticabal-SP, FCAVJUNESP.1992.160p.

26. RICE, E.L. Allelopathy. $2^{\text {nd }}$ ed, New York. Academic Press,
1984.

27. ROSA, S.G.T; FERREIRA, A.G. Germinação de sementes de plantas medicinais lenhosas. Acta Botânica Brasílica, São Paulo, v.15, n.2, p.147-154, 2001.

28. SIMÕES, C.M.O.; MENTZ, L.A.; SCHENKEL, E.P.;IRGANG,B.E. Plantas da Medicina Popular no Rio Grande do Sul. UFRGS. Porto Alegre. 1986. 212p.

29. YUNES, R. A.; CALIXTO, J. B. Plantas Medicinais sob a Ótica da Química Medicinal Moderna. Chapecó, Argos. 2001.120p. 